Article

\title{
Microstructure Transitions and Dry-Wet Spinnability of Silk Fibroin Protein from Waste Silk Quilt
}

\author{
Xin Zhang ${ }^{1}$ and Zhijuan Pan ${ }^{1,2, *}$ \\ 1 College of Textile and Clothing Engineering, Soochow University, Suzhou 215021, China; \\ zx18860901672@163.com \\ 2 National Engineering Laboratory for Modern Silk, Soochow University, Suzhou 215123, China \\ * Correspondence: zhjpan@suda.edu.cn; Tel.: +86-136-2527-3222
}

Received: 28 August 2019; Accepted: 2 October 2019; Published: 8 October 2019

\begin{abstract}
With excellent biocompatibility and biodegradability, silk fibroin has been developed into many protein materials. For producing regenerated silk fibroin (RSF) fibers, the conformation transition of silk fibroin needs to be thoroughly studied during the spinning process. Since the many silk fabrics that are discarded comprise an increasing waste of resources and increase the pressure on the environment, in this paper, waste silk fiber was recycled in an attempt to prepare regenerated fibroin fiber by dry-wet spinning. Ethanol was the coagulation bath. The rheological properties of all the RSF solutions were investigated to acquire rheology curves and non-Newtonian indexes for spinnability analysis. Four stages of the spinning process were carried out to obtain RSF samples and study their conformation transitions, crystallization, and thermal properties by Fourier transform infrared spectroscopy (FTIR), X-ray diffraction, and differential scanning calorimetry. Quantitative analysis of the FTIR results was performed to obtain specific data regarding the contents of the secondary structures. The results showed that higher concentration spinning solutions had better spinnability. As the spinning process progressed, random coils were gradually converted into $\beta$-sheets and crystallization increased. Among the different influencing factors, the ethanol coagulation bath played a leading role in the conformation transitions of silk fibroin.
\end{abstract}

Keywords: waste silk; regenerated silk fibroin; conformation transition; quantitative analysis; dry-wet spinning

\section{Introduction}

Bombyx mori silk is known as the "queen of fibers" because of its outstanding mechanical properties compared with most nature fibers. Silk fiber is a polymer composed of fibroin and glue-like sericin. Sericin, with the function of cohesion, coats the twin fibroin filaments together. After extraction from degummed silk fibers, firoin protein can be developed into various morphologies, including gels, sponges, films [1], and fibers, and combined with diverse functional materials to produce extraordinary properties. Currently, fibroin has broad application prospects in biomedical materials, such as tissue engineering scaffold materials [2,3] and fixed active material sensors [4], due to the excellent biocompatibility and tunable biodegradability [5] of this protein by virtue of its unique compositions and structure [6-9].

However, silk resources are very limited and precious due to their long production cycle and high cost. To solve this problem, many scholars have tried to extract silk fibroin to fabricate regenerated fibroin fibers. By simulating the spinning method of silkworms, people have expected to prepare superior regenerated silk fibroin fibers with an adjustable morphology and specific structure; further exploring the forming process and mechanisms of natural silk fibers could also promote significant development in the field of silk fibroin materials. Nevertheless, the performance of regenerated 
silk fibroin fibers developed based on current technical methods is still no match for that of natural silk fibroin fibers [10-12]. The relevant research on bionic protein fibers shows the importance of studying the relationship between protein conformation and function and the mechanism of the conformation transformation.

The secondary structure of silk fibroin has been extensively discussed relative to its structural transformation [13-15]. Common prominent secondary structures include random coils, $\alpha$-helices, $\beta$-sheets, and $\beta$-turns [16]. Random coils are characteristic conformations of macromolecules and are dominant in silk fibroin aqueous solution. The peptide chain of the $\alpha$-helix coils into a spiral around an imaginary central axis that is maintained by the hydrogen bonds within the chain. These two structures are related to the elasticity of silk fibroin fibers. In the $\beta$-sheet structure, multiple peptide chains or several peptides in a chain are arranged in parallel by oxygen bonds, and the serrated main chain forms a folded sheet, which is related to the strength of the silk fibroin fiber. As frequently occurring secondary structures in polypeptides, $\beta$-turns with common $180^{\circ}$ loops are composed of four amino acids [17].

Shimizu first reported the presence of two types of crystals in fibroin [18]. Later, Kratki et al. named these crystals Silk I and Silk II [19]. Currently, the crystalline structure of silk protein is mainly divided into an amorphous structure (Silk I) dominated by random coils and $\alpha$-helices and a stable structure (Silk II) dominated by $\beta$-sheets [20-22].

The secondary structures mentioned above are frequently detected when Fourier transform infrared spectroscopy (FTIR) [23-25] is used to characterize the construction transformation. FTIR, the earliest method used for this purpose, is quite practical and simple for detection of the peptide bonds of protein molecules containing various amide bonds. The amide I-III bands, including the secondary structure of protein molecules, can be very sensitive to detect. The amide I region is often used in quantitative analysis of the secondary structure with the second derivative, deconvolution, and curve fitting [26-30]. The structural changes in fibroin can be analyzed according to the crystallinity obtained by X-ray diffraction [31,32] and differential scanning calorimetry.

During the process of producing silk fabrics, there is a certain amount of waste material. In addition, large amounts of household silk textiles are discarded in garbage cans every year. In recent years, as the concept of the circular economy has grown, the public have begun to pay attention to the growing amounts of waste textiles. Germany, Britain, France, the United States, and Japan have passed legislative rules for the recycling of waste textiles and have established recycling systems. Since silk fibroin has the extraordinary characteristics mentioned above and is expensive due to a complex production process and high market demands, besides, using silk fabrics wastes may decrease breeding of silkworms, many scholars have carried out research related to the recycling and reuse of silk. To more effectively recycle and reuse waste silk, certain scientists treated waste silk by impregnation and melting without damaging the internal molecular composition to prepare composites [33-36]. Certain researchers found methods to destroy the molecular structure of waste silk by high temperature and high pressure or chemical reagent treatment, and successfully obtained silk sericin or fibroin protein [37,38].

Therefore, we tried to fabricate regenerated silk fibroin (RSF) fibers with fibroin extracted from waste silk fabric using dry-wet spinning equipment constructed in-house. Ethanol was chosen for the coagulation bath, and spinning solutions were prepared at four different concentrations. Since the spinnability of the fibroin from the RSF aqueous solutions still needed to be improved, the spinning solutions were tested by rheological measurement to obtain the non-Newtonian index (n). The apparent morphology, secondary structure, crystallization, and thermal properties of the RSF samples acquired at different stages were tested by scanning electron microscopy (SEM), Fourier transform infrared spectroscopy (FTIR), X-ray diffraction (XRD), and differential scanning calorimetry (DSC). 


\section{Materials and Methods}

\subsection{Materials}

Waste silk was obtained from discarded silk quilts used for over eight years. Ethanol was purchased from Chinasun Specialty Products Co., Ltd. (Jiangsu, China). The other chemical reagents, such as $\mathrm{LiBr}$ and $\mathrm{Na}_{2} \mathrm{CO}_{3}$, were analytical grade and used without further purification.

\subsection{Preparation of RSF Aqueous Solutions}

The waste silk was degummed by boiling in $0.2 \mathrm{wt} \% \mathrm{Na}_{2} \mathrm{CO}_{3}$ aqueous solution for $25 \mathrm{~min}$ and then was washed several times with deionized water. The waste silk fibroin was allowed to air dry overnight at room temperature. A $10 \%(\mathrm{w} / \mathrm{v})$ solution of degummed waste silk fibroin in $9.3 \mathrm{~mol} / \mathrm{L}$ $\mathrm{LiBr}$ aqueous solution was prepared by heating to $60{ }^{\circ} \mathrm{C}$ for $1 \mathrm{~h}$ with continuous stirring. After dialysis against deionized water by a cellulose semipermeable membrane (MWCO: $14 \mathrm{kDa}$ ) at room temperature for 3 days to remove salts, the RSF aqueous solution was centrifuged at $6000 \mathrm{r} / \mathrm{min}$ for $6 \mathrm{~min}$ to remove impurities. RSF aqueous solutions with the desired concentrations, i.e., 19, 22, 25 and $28 \mathrm{wt} \%$, were prepared by dialysis against a $15 \%(\mathrm{w} / \mathrm{v})$ polyethylene glycol (PEG) solution.

\subsection{Dry-Wet Spinning of RSF Aqueous Solutions}

The silk fibroin fibers were spun through dry-wet spinning equipment constructed in-house. The solutions were extruded through a spinneret $0.26 \mathrm{~mm}$ in diameter at room temperature using a syringe and pump. Through the air gap, the solution went into the $100 \%$ ethanol coagulation bath. The extrusion flow rate was $5 \mathrm{~mL} / \mathrm{min}$.

\subsection{Preparation of Test Samples}

According to the spinning process, four stages of silk fibroin proteins were selected for exploring the conformation transformation: (1) the spinning solutions, (2) the spinning solutions extruded through the spinneret before contacting the coagulation bath, (3) the spinning solutions just entering the coagulation bath, and (4) the spinning solutions treated by the coagulation bath for a certain amount of time. Stages (1) and (2) were liquid RSF samples with different concentrations that were cast on polyethylene plates at $25^{\circ} \mathrm{C}$ to form films. Stages (3) and (4) were deformed coagulated samples or RSF fibers formed from the various concentrations that were dried overnight at $25^{\circ} \mathrm{C}$ after washing by deionized water to remove the residue from the coagulation bath. The 16 sample codes are shown in Table 1.

Table 1. Sample codes of various concentrations of regenerated silk fibroin (RSF) from 4 stages of the spinning process.

\begin{tabular}{|c|c|c|c|c|c|}
\hline Sample Code ${ }^{1}$ & Concentration/wt $\%$ & Stage & Sample Code ${ }^{1}$ & Concentration/wt $\%$ & Stage \\
\hline 19-F1 & 19 & (1) & 25-F1 & 25 & (1) \\
\hline $19-\mathrm{F} 2$ & 19 & (2) & 25-F2 & 25 & (2) \\
\hline 19-E1 & 19 & (3) & 25-E1 & 25 & (3) \\
\hline 19-E2 & 19 & (4) & 25-E2 & 25 & (4) \\
\hline 22-F1 & 22 & (1) & 28-F1 & 28 & (1) \\
\hline $22-\mathrm{F} 2$ & 22 & (2) & 28-F2 & 28 & (2) \\
\hline 22-E1 & 22 & (3) & 28-E1 & 28 & (3) \\
\hline 22-E2 & 22 & (4) & 28-E2 & 28 & (4) \\
\hline
\end{tabular}

${ }^{1}$ The number in the code represents the concentration of the spinning solution; F1: the sample was in film form in the first stage; F2: the sample was in film form in the second stage; E1: the sample was in ethanol coagulation in the third stage; E2: the sample was in ethanol coagulation in the fourth stage. 


\section{Characterization and Evaluation}

The Fourier transform infrared spectroscopy (FTIR) spectra were obtained on a Nicolet iS5 spectrophotometer (Thermal Fisher Scientific, Madison, WI, USA) in the wavenumber range of $800-1800 \mathrm{~cm}^{-1}$. A total of 16 scans were accumulated with a resolution of $4 \mathrm{~cm}^{-1}$ for each spectrum. All the FTIR spectra presented in this work are smoothed absorption data, corrected by background calibration and normalization.

The rheology of all the solutions was measured on a rotational rheometer (Discovery HR-2, TA Instruments, New Castle, DE, USA). The $40 \mathrm{~mm}$ diameter cone plate geometry was used for the solutions. The chosen gap was $26 \mu \mathrm{m}$ for all the solutions. Continuous ramp step experiments were examined at a shear-rate range of 0.1 to $100 \mathrm{~s}^{-1}$ at $25^{\circ} \mathrm{C}$. Each sample was made and tested three times to avoid errors.

The crystalline structure of all the samples were performed by $X$-ray diffraction $(X R D)$ using the $X^{\prime}$ Pert Pro MPD X-ray diffraction system (PAN analytical, Eindhoven, Holland) with a CuK $\alpha$ radiation source (wavelength, $\lambda=0.154 \mathrm{~nm}$ ) of $40 \mathrm{kV}$ and $30 \mathrm{~mA}$. The XRD diffraction spectra were recorded in the $2 \theta$ range $5-45^{\circ}$ at a scan rate of $3^{\circ} / \mathrm{min}$.

Differential scanning calorimetry (DSC) was performed on approximately $5 \mathrm{mg}$ of material in an open crucible using a Q2000 calorimeter (TA Instruments, New Castle, DE, USA) under nitrogen flow. A heating rate of $20^{\circ} \mathrm{C} / \mathrm{min}$ was used for standard DSC analysis. The DSC process is shown in Figure 1. The temperature was raised from 0 to $200{ }^{\circ} \mathrm{C}$ (black dashed line), held for $2 \mathrm{~min}$ at $200^{\circ} \mathrm{C}$ (red dotted line), and decreased to $0^{\circ} \mathrm{C}$ (blue dashed and dotted line) at the same rate to eliminate the influences of moisture and internal stress in the samples. After the isothermal temperature was maintained for $2 \mathrm{~min}$ (magenta dashed and dotted line), the temperature was increased to $200{ }^{\circ} \mathrm{C}$ again (green solid line) at the rate of $20^{\circ} \mathrm{C} / \mathrm{min}$ to obtain an accurate glass transition temperature.

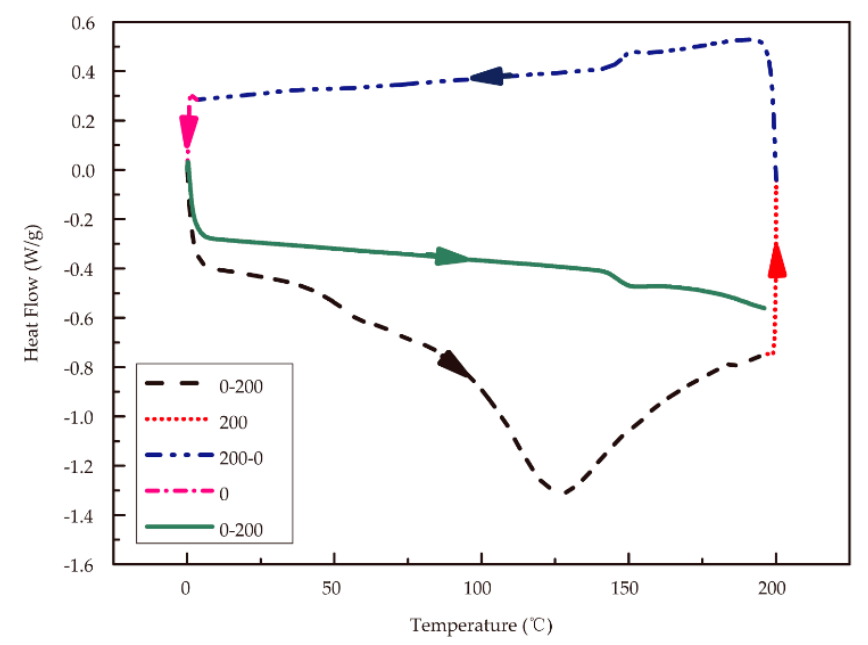

Figure 1. Heat-cool-reheat differential scanning calorimetry (DSC) scan process for RSF samples.

Images of the RSF fibers were taken on a scanning electron microscope (SEM) (S4800, Hitachi, Tokyo, Japan) at a voltage of $3 \mathrm{kV}$.

\section{Results and Discussion}

\subsection{Rheological Behaviors of RSF Solutions with Various Concentrations}

In Figure 2, the viscosity of the RSF aqueous solutions decreased with increasing shear rate, and the solutions exhibited typical shear thinning behavior with variation of the shear rate, indicating that all the solutions behaved as non-Newtonian fluids. 


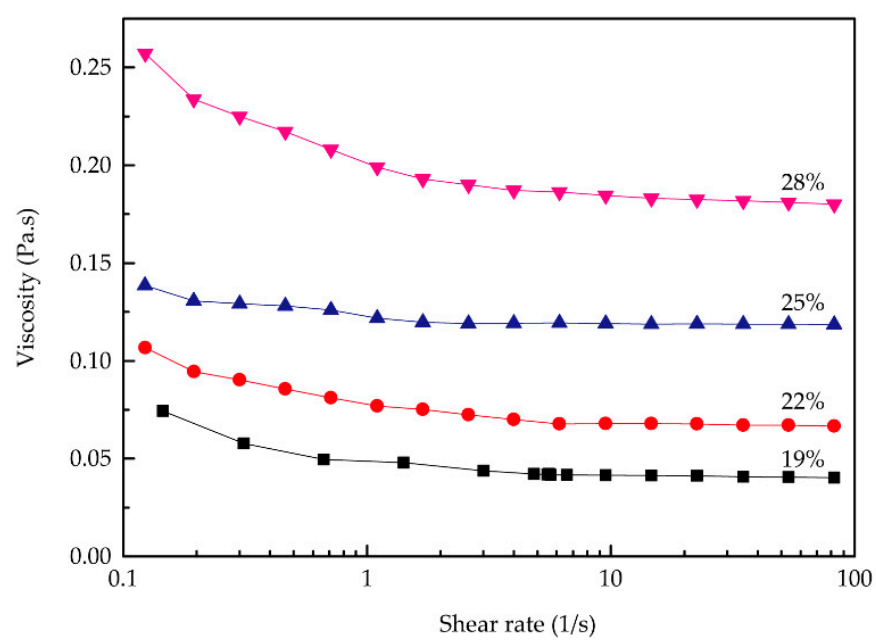

Figure 2. Rheological curves of the RSF solutions with different concentrations.

All the spinning solutions could be characterized by a power-law equation [39]:

$$
\mathrm{T}=\mathrm{K} \cdot \gamma \mathrm{n}
$$

where $\tau$ represents shear stress, $\gamma$ is the shear rate, $K$ is the consistency coefficient, and $n$ is the non-Newtonian index. The logarithm of both sides of Equation (1) was taken, yielding Equation (2) as follows:

$$
\operatorname{Lg} \tau=\mathrm{K}+\operatorname{nlg} \gamma
$$

Comparisons of the estimated (red lines) and experimental (line and squares) $\lg \tau-\lg \gamma$ curves are shown in Figure 3 for various concentrations of RSF solutions:
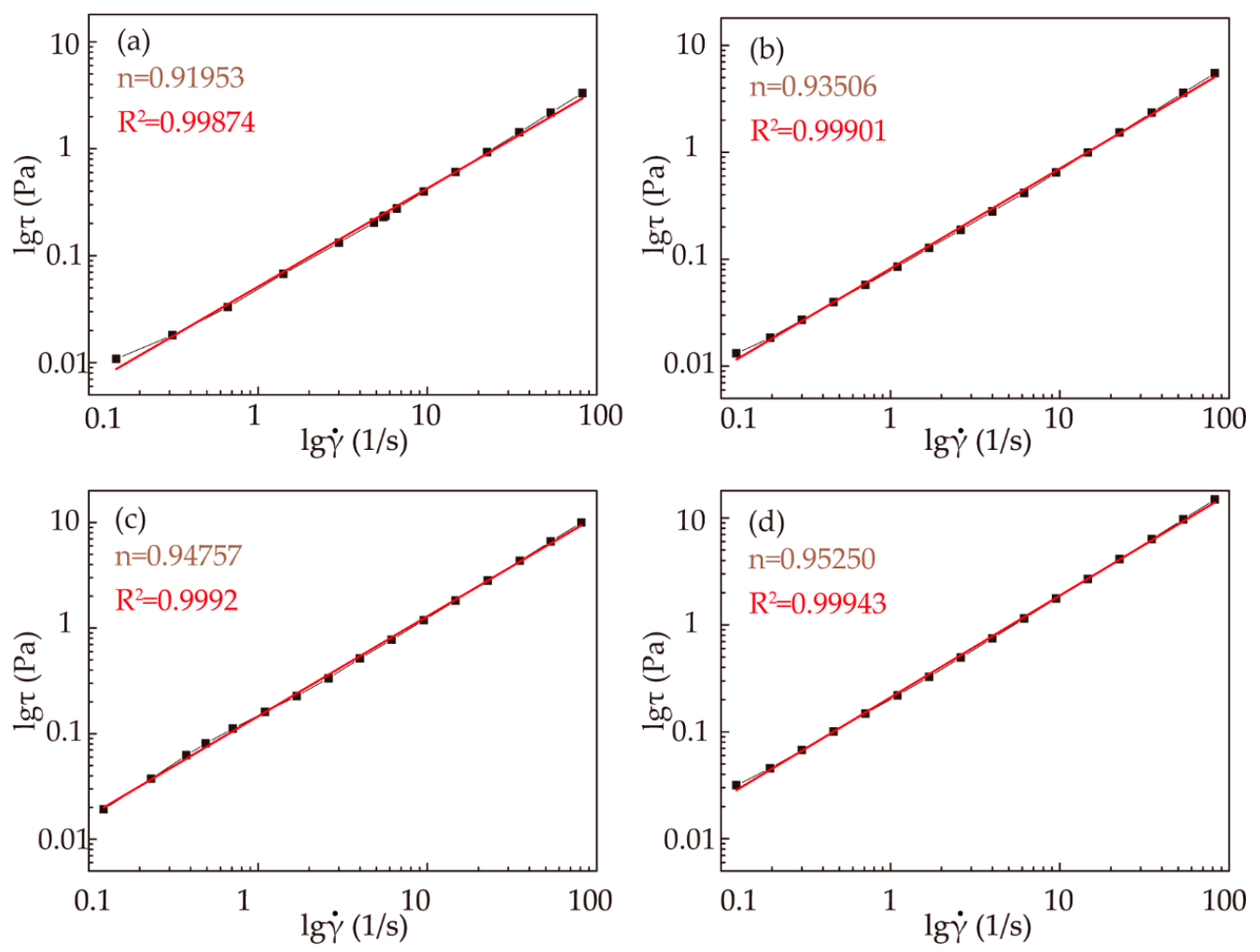

Figure 3. Rheological behavior fitting results of RSF solutions with different concentrations: (a) 19\%; (b) $22 \%$; (c) $25 \%$; (d) $28 \%$. 
The fitting results of $\mathrm{n}$ values for the RSF solutions are shown in Figure 3. All the fluids studied had $\mathrm{n}<1$, indicating that all the fibroin solutions were pseudoplastic fluids. With increasing solution concentration, $\mathrm{n}$ approached 1 , indicating that the fluidity and spinnability of the RSF solutions increased. However, it takes a longer time to obtain a higher concentration of the solution, and as the concentration increases, the RSF solution is prone to deformation. Therefore, obtaining the spinning solution with a concentration over $28 \%$ is more difficult.

\subsection{Conformation Analysis of RSF Samples from FTIR Spectra}

FTIR spectroscopy was used to study the conformational states of the RSF samples. The FTIR absorptions of silk fibroin conformations are reported in Table $2[40,41]$.

Table 2. Infrared absorptions of silk fibroin conformations.

\begin{tabular}{cccc}
\hline Fibroin Conformation & Amide I $/ \mathbf{c m}^{\mathbf{- 1}}$ & Amide II $/ \mathbf{c m}^{\mathbf{- 1}}$ & Amide III $/ \mathbf{c m}^{\mathbf{- 1}}$ \\
\hline$\beta$-sheet & $1622-1637$ & $1515-1525$ & 1265 \\
$\alpha$-helix & $1656-1662$ & 1545 & 1240 \\
Random coil & $1638-1655$ & $1535-1545$ & 1235 \\
\hline
\end{tabular}

Figure 4 shows the infrared absorption spectra of the RSF samples with different concentrations in four stages, displaying amide I, II, and III absorption bands. As shown in Figure 4a, the trends of the four spectra were mostly similar; the RSF films exhibited absorption bands at $1514-1517 \mathrm{~cm}^{-1}$ (amide II), corresponding to the $\beta$-sheet conformation, and $1639-1640 \mathrm{~cm}^{-1}$ (amide I), $1528-1530 \mathrm{~cm}^{-1}$ (amide II), and 1236-1237 $\mathrm{cm}^{-1}$ (amide III), corresponding to the random coil conformation. According to Arrondo et al. [42], the spectral bands between 1620 and $1625 \mathrm{~cm}^{-1}$ were the interchain structures, while the spectral bands between 1630 and $1637 \mathrm{~cm}^{-1}$ were the intrachain structures. Comparing Figure $4 \mathrm{a}, \mathrm{b}$, after extrusion through the spinneret into the air gap, the amide I peaks of samples in Figure $4 \mathrm{~b}$ obviously shifted to lower wavenumbers (from $1639-1640 \mathrm{~cm}^{-1}$ to $1624-1625 \mathrm{~cm}^{-1}$ ), remaining shoulders at $1631-1640 \mathrm{~cm}^{-1}$. The intensity of the shoulder at approximately $1531-1534 \mathrm{~cm}^{-1}$ of amide II decreased slightly compared with the similar peaks in Figure 4a, while the peaks in amide III scarcely shifted from $1236-1237 \mathrm{~cm}^{-1}$ to $1235-1236 \mathrm{~cm}^{-1}$, corresponding to the random coil conformation.

As shown in Figure 4c, after entering the ethanol coagulation bath, the characteristic peaks of amides I, II, and III all underwent distinct wave shifts to lower wavenumbers, while the shoulder peaks of amides I and II disappeared and the width of characteristic peaks narrowed. It was noteworthy that, in Figure $4 c, d$, the obvious shoulders at $1693-1695 \mathrm{~cm}^{-1}$ and $1694-1695 \mathrm{~cm}^{-1}$ respectively appeared corresponding to antiparallel structure [43], showing that ethanol greatly influenced the conformation of the RSF. The amide II peaks, compared with Figure $4 \mathrm{~b}$, shifted from $1531-1534 \mathrm{~cm}^{-1}$ to $1514-1522 \mathrm{~cm}^{-1}$, corresponding to random coils and $\beta$-sheets [44-46], respectively. This result confirmed that the ethanol had a strong ability to change the silk fibroin from the random coil conformation to the $\beta$-sheet conformation. The position and number of peaks in Figure $4 \mathrm{~d}$ were slightly different than those of Figure $4 c$, while the peaks of amides II and III shifted slightly to lower wavenumbers, meaning that the coagulation bath treatment time had a certain effect on the structural transformation. 


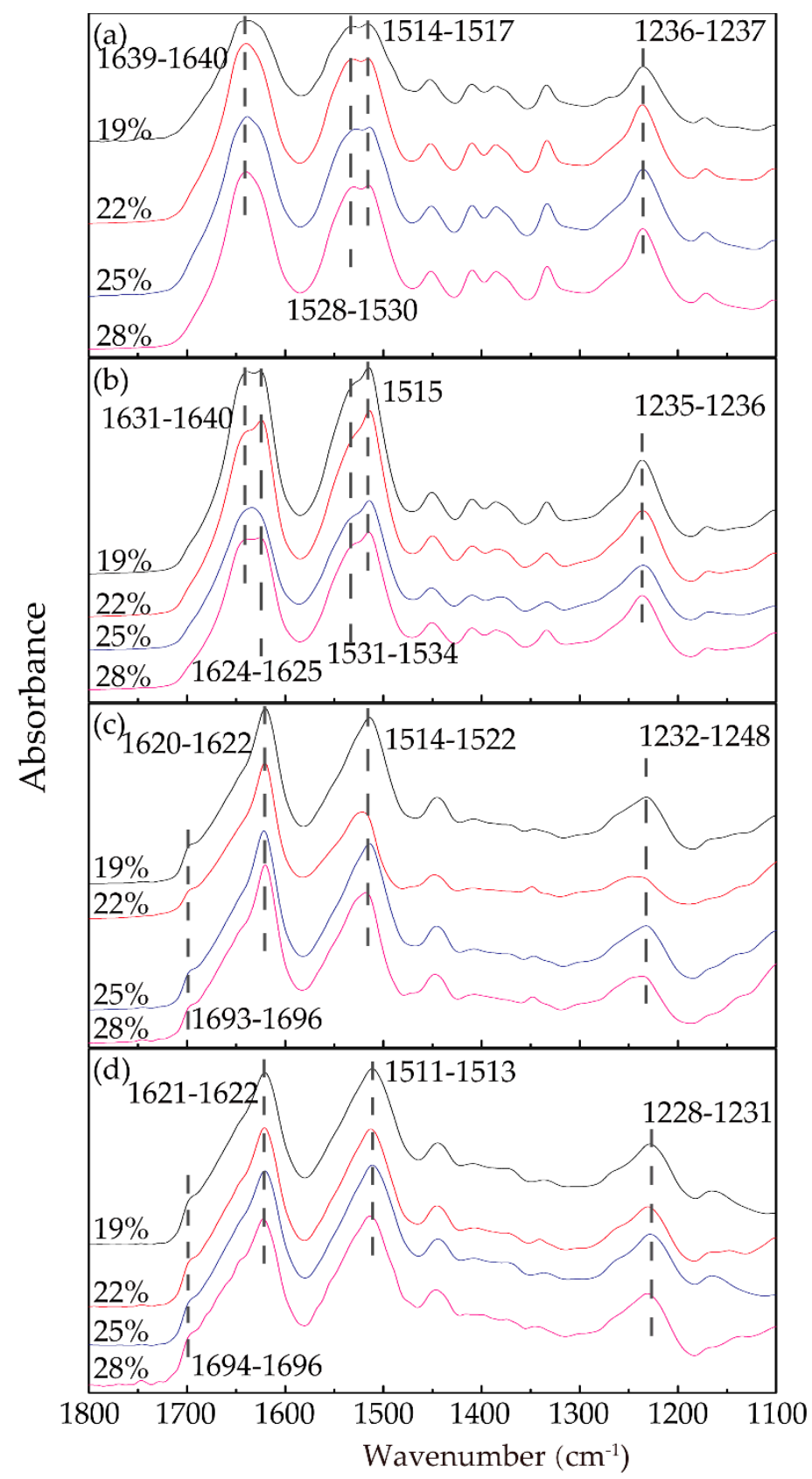

Figure 4. FTIR spectra of all the samples from the amide I to amide III bands: (a) F1; (b) F2; (c) E1; (d) E2.

\subsection{Estimation of $\beta$-sheet Content in Samples Using Amide I Band from FTIR Spectra}

The amide I band $\left(1600-1700 \mathrm{~cm}^{-1}\right)$ was selected for quantitative analysis of the secondary structure of RSF samples [42]. The spectra were smoothed to remove the influence of vapor. The second-derivative spectra were calculated to obtain the positions of the secondary structures, and the deconvolution spectra were acquired by the conservative values of a full width at half maximum (FWHH) of $13.0 \mathrm{~cm}^{-1}$ and a resolution enhancement factor of 2.4 to reverse the effects of convolution on the recorded data, as shown in Figure 5. Peak fitting (Origin) software (v4.12) was used to fit the curve of the deconvolution spectrum of the sample with the Gauss and Lorentz Amp functions until the fitting degree was close to 1, as shown in Figure 5. After adding up the area of sub-spectra corresponding to each secondary structure and calculating the percentage of the area occupied by these sub-spectra, respectively, the content (\%) of each secondary structure can be calculated quantitatively. 


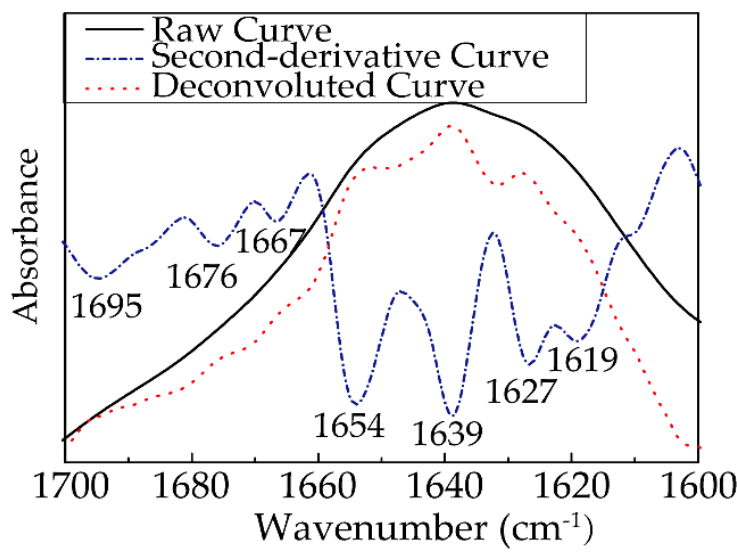

(a)

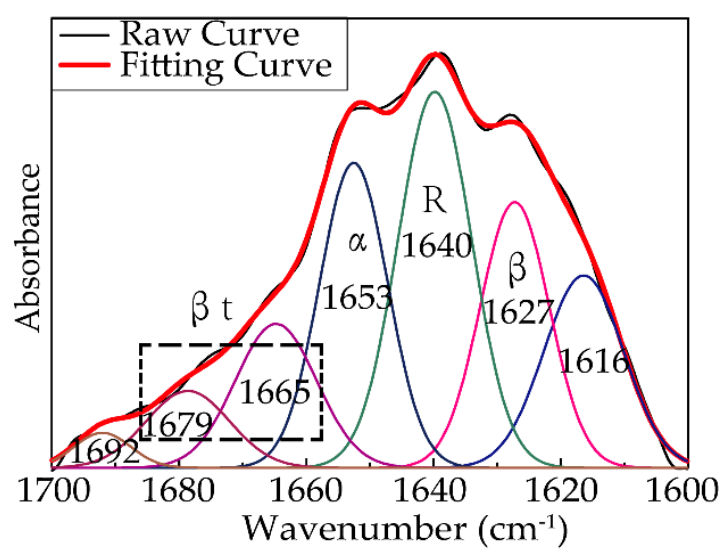

(b)

Figure 5. (a) Raw curve (black line), deconvoluted curve (red dotted line), and second-derivative curve (blue dashed and dotted line) of the amide I absorption band of 25-F1 sample; (b) The quantitative analysis of the amide I band for 25-F1 sample (the black line is the original spectrum, the red line is the fitting spectrum, and the colorful lines are the contributions to the spectra from each type of secondary structure).

The relative intensity of the spectra of amide I provided the fractional secondary structure contents of random coils (black circles), $\beta$-sheets (red squares), $\alpha$-helices (blue triangles), and $\beta$-turns (magenta inverted triangles) in each sample, shown in Figure 6. In the first (F1) and second (F2) stages, the secondary structure distributions were similar. The dominant secondary structure was random coils, followed by $\beta$-sheets. With increasing concentration, the random coil content first decreased and then increased as the concentration increased to $28 \%$, and the $\beta$-sheet content did not vary much with concentration in the first two stages, while the $\alpha$-helix and $\beta$-turn contents were similarly low.
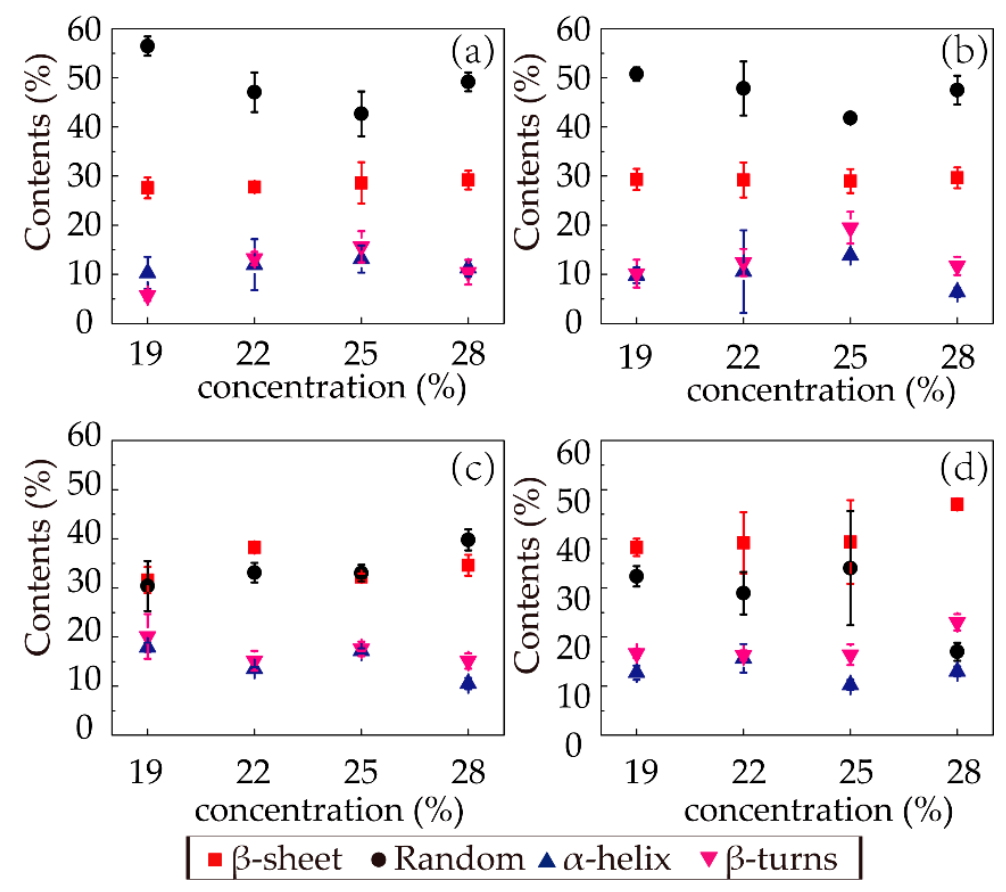

Figure 6. Contents of secondary structures in the RSF samples: (a) F1; (b) F2; (c) E1; (d) E2. 
In the third stage (E1), the random coil contents of the samples with different concentrations all significantly decreased (from 50.76, 47.83, 41.80, and $47.49 \%$ to $30.38,33.09,33.01$, and $39.77 \%$, respectively), with obvious increases in the $\beta$-sheet contents (from 29.31, 29.21, 28.99, and $29.64 \%$ to $31.59,38.22,32.23$, and $34.61 \%$ ). This phenomenon confirmed that the coagulation had a strong ability to transform the structure from random coil to $\beta$-sheet. Regarding the fourth stage (E2), the trends of decreasing random coil content and increasing $\beta$-sheet content with increasing concentration were distinct, while the $\alpha$-helix and $\beta$-turn contents experienced slight irregular fluctuations. Since the $\beta$-sheet content was relevant to the performance, the $\beta$-sheet distribution in the last stage was noteworthy. With increasing concentration, the $\beta$-sheet content gradually increased with an increment from 34.61 to $47.00 \%$ in sample 28 -E2. This result indicated that the spinning solutions with high concentrations better facilitated the formation of $\beta$-sheets of silk fibroin protein through ethanol coagulation in the same amount of time.

\subsection{Crystallinity Analysis of Silk Fibroin Protein Samples}

\subsubsection{X-Ray Diffraction (XRD)}

As the most well-known secondary structures, Silk I and Silk II have been extensively analyzed by XRD. Silk I, corresponding to the $\alpha$-helix conformation, is the metastable structure of fibroin. Silk II, corresponding to the $\beta$-sheet structure, is a conformation where all the molecular chains run in alternate directions and form stable antiparallel chain pleated sheets. The transformation from Silk I to Silk II has always been regarded as an important indicator of $\beta$-sheet crystallization. Silk I shows three main diffraction peaks at approximately $2 \theta=12.2,19.7$, and $24.7^{\circ}$, while Silk II diffraction peaks are located at approximately $2 \theta=9.1^{\circ}$ and $20.7^{\circ}$ [47]. The XRD spectra of the RSF samples are presented in Figure 7. Taking samples 19-F1, 19-F2, 19-E1, and 19-E2 as examples, sample 19-F1 exhibited three main diffraction peaks at $2 \theta=12.2,20.0$, and $23.4^{\circ}$, assigned to Silk I, and these three peaks of shifted slightly to $11.8,19.8$ and $22.7^{\circ}$, respectively, for sample 19-F2 but were still the characteristic peaks of Silk I. Nevertheless, Silk II diffraction peaks started to emerge in samples 19-E1 (10.1 and 20.3 $)$ and 19-E2 (10.4 and 20.8 ${ }^{\circ}$, with only one Silk I diffraction peak remaining at $23.9^{\circ}$ and $23.6^{\circ}$ in these two stages, respectively. This phenomenon suggested that the crystallinity of the samples treated by ethanol increased. Additionally, for samples with different concentrations, the trends of the peak shifts were incredibly similar; in the first stage, all three characteristic peaks represented Silk I, and in the second stage, most of the peaks shifted but remained Silk I. As the concentration increased, the characteristic peaks of samples 25-F2 and 28-F2 started to shift to Silk II diffraction peaks, meaning that high concentration improved the crystallinity. In the last two stages, all the samples with various concentrations showed distinct Silk II diffraction peaks, while the position of the Silk I diffraction peaks at approximately $24.7^{\circ}$ did not change much among all the stages. The number of miscellaneous peaks decreased, and the curves smoothed as the spinning progressed. The aforementioned results showed that all the stages increased the crystallinity and increasing concentration positively impacted the crystallinity. The ethanol strongly induced the Silk II ( $\beta$-sheet) structure, improving the crystallinity. 

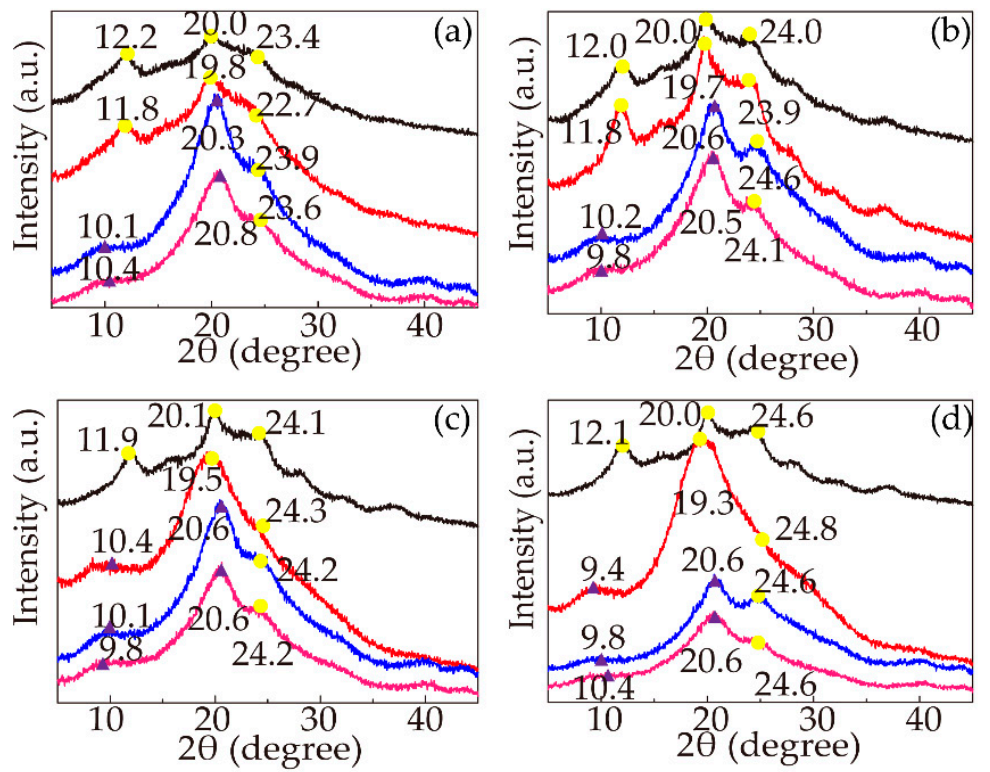

$-\mathrm{F} 1-\mathrm{F} 2-\mathrm{E} 1-\mathrm{E} 2$

Figure 7. X-ray spectra of all the RSF samples (the yellow points represent Silk I, and the purple triangles represent Silk II): (a) 19\%; (b) 22\%; (c) 25\%; (d) 28\%.

\subsubsection{Differential Scanning Calorimetry (DSC)}

The heat-cool-reheat process was used to evaporate the intermolecular bound water and obtain an accurate glass transition temperature. A clear glass transition temperature could be detected during the last run of the DSC curve (cool-reheat), and the glass transition temperatures of all the RSF samples are reported in Figure 8. The curves clearly show that the differences in the glass transition temperatures $\left(T_{g}\right)$ of all the sample were negligible, meaning that the thermodynamic stabilities of the samples were similar.
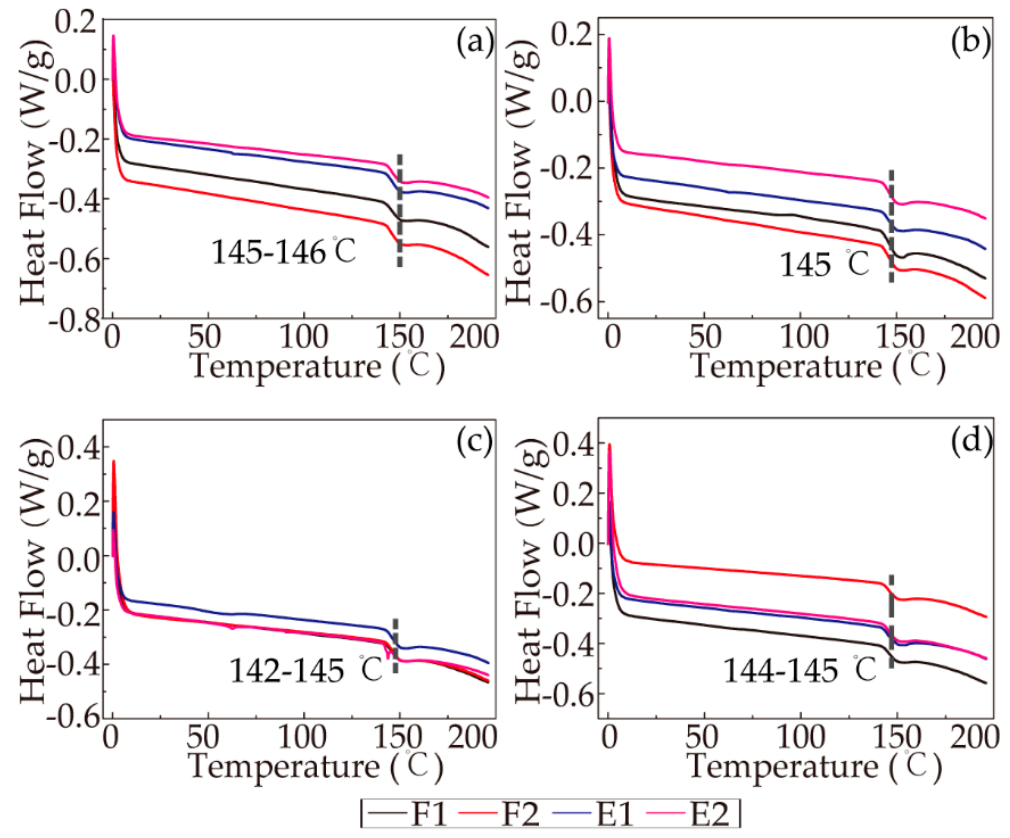

Figure 8. DSC curves of the cool-reheat scans: (a) 19\%; (b) 22\%; (c) 25\%; (d) $28 \%$. 
In addition to the glass transition temperature, the variation in the heat capacity $\left(\Delta c_{p}\right)$ at $T_{g}$ was a key measurement. Because $\Delta c_{p}$ is proportional to the amorphous content in the sample, an increase in the crystallinity results in a decrease in the $\Delta \mathrm{c}_{\mathrm{p}}$. Thus, the degree of crystallinity in the samples could be roughly determined based on the following equation:

$$
\Delta \mathrm{c}_{\mathrm{p}}=\left|\frac{\Phi_{2}-\Phi_{1}}{m \beta}\right|
$$

where $\Phi 1$ and $\Phi 2$ represent the onset and end of the glass transformation from the DSC signal (heat flows), respectively, $\mathrm{m}$ is the sample quality, and $\beta$ is the heating rate. The distinctive specific results of all the samples are exhibited in Figure 9; with increasing concentration, $\Delta c_{p}$ decreased for almost every stage except the third stage (E1), as demonstrated by sample 28-E1, which showed with the increasing concentration, the degree of crystallization became higher to some extent. With the progression of the spinning process, the $\Delta c_{p}$ of all the samples decreased except for sample 25-F2. In addition, the degree of the decrease in the $\Delta c_{p}$ was most significant between F2 and E1, followed by ethanol coagulation treatment and air gap treatment. In summary, the ethanol coagulation played an important role in promoting the crystallinity of the silk fibroin, while the four stages all affected the crystallinity to an extent. The conclusions were consistent with the results mentioned above.

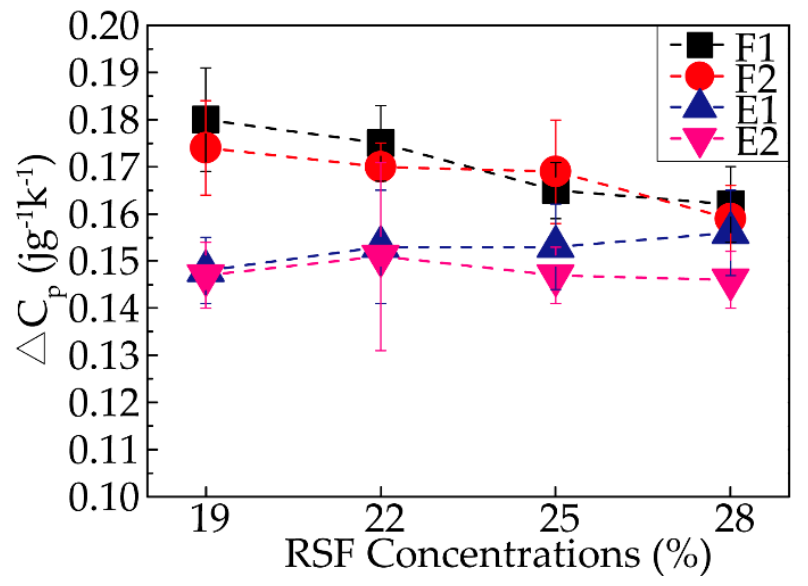

Figure 9. Variations in the heat capacities $\left(\Delta c_{p}\right)$ of all the RSF samples.

\subsection{Morphology of the Coagulated Samples}

Figure 10 shows images of the spinning conditions of the RSF solutions treated by the ethanol coagulation bath (Figure 10a-d). The effect of concentration during dry-wet spinning of the RSF fibers was obvious in the ethanol coagulation bath. Figure 10a shows that the solution quickly diffused into the coagulation bath; Figure $10 \mathrm{~b}$ shows that the solution coagulated discontinuously; Figure 10c shows that bead shaped RSF started to form. The low concentration solution had difficulties forming fibers in the ethanol coagulation bath, while the $28 \%$ RSF solution successfully formed continuous fibers, as shown in Figure 10d. The experimental results were consistent with the rheological test results showing that increasing concentration increased the spinnability. SEM images of the surface of sample 28 -E2 are shown in Figure 10e at 1500× and 10,000x. The fibers displayed rough morphology with obvious and irregular grooves, possibly from the drafting process. The surface of the as-spun fibers was rough. Further improvement is still needed to optimize the apparent morphology of the fibers. 


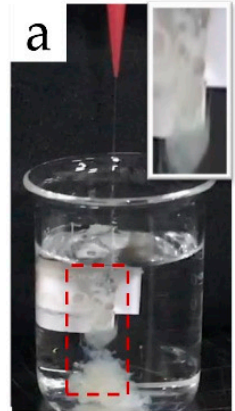

$19 \%$

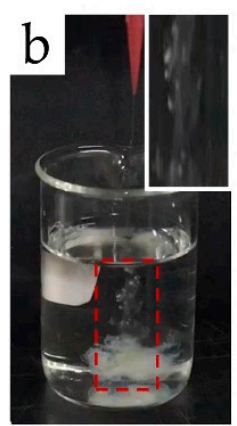

$22 \%$

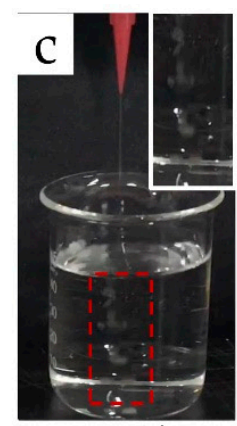

$25 \%$

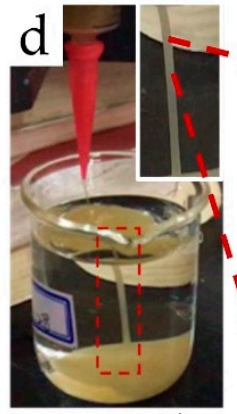

$28 \%$

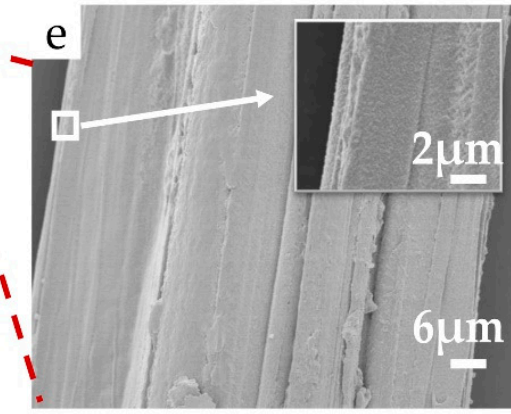

Figure 10. (a-d) Effect of concentration on the dry-wet spinnability of the RSF solutions; (e) Morphology of the RSF fibers (28-E2).

\section{Conclusions}

In this paper, silk fibroin was extracted from waste silk to prepare a regenerated fibroin solution. To study the spinnability of this kind of RSF solution, dry-wet spinning was used to attempt to fabricate regenerated silk fibroin fibers with a device constructed in-house. Adjusting the concentrations of the RSF solutions, spinning solutions with concentrations of $19,22,25$, and $28 \mathrm{wt} \%$ were obtained to study the effect of the concentration on spinnability. The coagulation bath was a $100 \%$ ethanol solution. According to the steps of the spinning process, RSF samples from the spinning solution, air gap, and ethanol coagulation bath for a short period of time, and from the ethanol coagulation bath for a long period of time were chosen to investigate the conformation transitions of silk fibroin. Rheological measurements showed that all the spinning solutions behaved as non-Newtonian fluids and that an increasing concentration improved spinnability according to the non-Newtonian index. Comparing the FTIR results of all the RSF samples, coagulation in ethanol was able to induce silk fibroin to transform from the random coil to the $\beta$-sheet conformation, followed by the concentration of the spinning solution, the air gap, and coagulation treatment time. The XRD results and DSC proved the conclusions. Due to the low viscosity of the RSF solutions extracted from the waste silk, the spinning conditions were not good. Only when the concentration reached $28 \mathrm{wt} \%$ was the spinning solution able to present continuous fibers in the ethanol coagulation bath. However, the surface of the RSF fibers was rough and damaged, and much work remains to optimize the spinnability of the RSF solution.

Author Contributions: X.Z. conceived, designed and performed the experiments; X.Z. and Z.P. analysed the data and wrote the paper; Z.P. proofread the technical content.

Funding: This research received no external funding.

Conflicts of Interest: The authors declare no conflict of interest.

\section{References}

1. Jin, H.J.; Park, J.; Karageorgiou, V.; Kim, U.J.; Valluzzi, R.; Cebe, P.; Kaplan, D.L. Water-Stable Silk Films with Reduced $\beta$-Sheet Content. Adv. Funct. Mater. 2005, 15, 1241-1247. [CrossRef]

2. Bhardwaj, N.; Kundu, S.C. Electrospinning: A fascinating fiber fabrication technique. Biotechnol. Adv. 2010, 28, 325-347. [CrossRef] [PubMed]

3. Dhasmana, A.; Singh, L.; Roy, P.; Mishra, N.C. Silk fibroin protein modified acellular dermal matrix for tissue repairing and regeneration. Mater. Sci. Eng. C Mater. Biol. Appl. 2019, 97,313-324. [CrossRef]

4. Shi, Y.; Li, Z.; Shi, J.; Zhang, F.; Zhou, X.; Li, Y.; Holmes, M.; Zhang, W.; Zou, X. Titanium dioxide-polyaniline/silk fibroin microfiber sensor for pork freshness evaluation. Sens. Actuators B 2018, 260, 465-474. [CrossRef]

5. Jao, D.; Xue, Y.; Medina, J.; Hu, X. Protein-Based Drug-Delivery Materials. Materials 2017, 10, 517. [CrossRef] [PubMed] 
6. Bhardwaj, N.; Singh, Y.P.; Devi, D.; Kandimalla, R.; Kotoky, J.; Mandal, B.B. Potential of silk fibroin/chondrocyte constructs of muga silkworm Antheraea assamensis for cartilage tissue engineering. J. Mater. Chem. B 2016, 4, 3670-3684. [CrossRef]

7. Yu, S.; Yang, W.; Chen, S.; Chen, M.; Liu, Y.; Shao, Z.; Chen, X. Floxuridine-loaded silk fibroin nanospheres. RSC Adv. 2014, 4, 18171-18177. [CrossRef]

8. Hu, X.; Wang, X.; Rnjak, J.; Weiss, A.S.; Kaplan, D.L. Biomaterials derived from silk-tropoelastin protein systems. Biomaterials 2010, 31, 8121-8131. [CrossRef]

9. Hu, X.; Shmelev, K.; Sun, L.; Gil, E.S.; Park, S.H.; Cebe, P.; Kaplan, D.L. Regulation of silk material structure by temperature-controlled water vapor annealing. Biomacromolecules 2011, 12, 1686-1696. [CrossRef]

10. Vepari, C.; Kaplan, D.L. Silk as a Biomaterial. Prog. Polym. Sci. 2007, 32, 991-1007. [CrossRef]

11. Perez-Rigueiro, J.; Madurga, R.; Ganan-Calvo, A.M.; Elices, M.; Guinea, G.V.; Tasei, Y.; Nishimura, A.; Matsuda, H.; Asakura, T. Emergence of supercontraction in regenerated silkworm (Bombyx mori) silk fibers. Sci. Rep. 2019, 9, 2398. [CrossRef] [PubMed]

12. Wojcieszak, M.; Percot, A.; Colomban, P. Regenerated silk matrix composite materials reinforced by silk fibres: Relationship between processing and mechanical properties. J. Compos. Mater. 2017, 52, 2301-2311. [CrossRef]

13. Ks, S.; Si, I.; Nr, M. Regularities in Variation of Support Functions of Physically Nonlinear Elastic-Visco-Plastic Law of Strain of Cotton Yarn. J. Fash. Technol. Text. Eng. 2018, 6. [CrossRef]

14. Zhou, Y.; Tang, R.C. Natural Flavonoid-Functionalized Silk Fiber Presenting Antibacterial, Antioxidant, and UV Protection Performance. ACS Sustain. Chem. Eng. 2017, 5, 10518-10526. [CrossRef]

15. Drummy, L.F.; Phillips, D.M.; Stone, M.O.; Farmer, B.L.; Naik, R.R. Thermally Induced alpha-Helix to beta-Sheet Transition in Regenerated Silk Fibers and Films. Biomacromolecules 2005, 6, 3328-3333. [CrossRef] [PubMed]

16. Marie Eve, R.; Lilyane, B.; Thierry, L.; Joanie, P.; Tetsuo, A.; Michel, P. Characterization by Raman microspectroscopy of the strain-induced conformational transition in fibroin fibers from the silkworm Samia cynthia ricini. Biomacromolecules 2006, 7, 2512-2521. [CrossRef]

17. David, E. The discovery of the alpha-helix and beta-sheet, the principal structural features of proteins. Proc. Natl. Acad. Sci. USA 2003, 100, 11207-11210. [CrossRef]

18. Shimizu, M. Eine röntgenographische Untersuchung des Sericins. Bull. Sericult. Exp. Stn. 1941, 10, 441-474.

19. Lotz, B.; Brack, A.; Spach, G. $\beta$ Structure of periodic copolypeptides of l-alanine and glycine: Their relevance to the structure of silks. J. Mol. Biol. 1974, 87, 193-203. [CrossRef]

20. Kratky, O.; Schauenstein, E.; Sekora, A. An Unstable Lattice in Silk Fibroin. Nature 1950, 165, 319-320. [CrossRef]

21. He, S.J.; Valluzzi, R.; Gido, S.P. Silk I structure in Bombyx mori silk foams. Int. J. Biol. Macromol. 1999, 24, 187-195. [CrossRef]

22. Asakura, T.; Ashida, J.; Yamane, T.; Kameda, T.; Nakazawa, Y.; Ohgo, K.; Komatsu, K. A repeated beta-turn structure in poly(Ala-Gly) as a model for silk I of Bombyx mori silk fibroin studied with two-dimensional spin-diffusion NMR under off magic angle spinning and rotational echo double resonance. J. Mol. Biol. 2001, 306, 291-305. [CrossRef] [PubMed]

23. Zhang, X.; Wyeth, P. Using FTIR spectroscopy to detect sericin on historic silk. Sci. China Chem. 2010, 53, 626-631. [CrossRef]

24. Sionkowska, A.; Planecka, A. The influence of UV radiation on silk fibroin. Polym. Degrad. Stab. 2011, 96, 523-528. [CrossRef]

25. Arai, T.; Freddi, G.; Innocenti, R.; Tsukada, M. Biodegradation of Bombyx mori silk fibroin fibers and films. J. Appl. Polym. Sci. 2010, 91, 2383-2390. [CrossRef]

26. Li, D.; Hong, Z.; Gang, M. Secondary structure investigation of bovine serum albumin (BSA) by Fourier transform infrared (FTIR) spectroscopy in the amide III region. Eur. J. Chem. 2014, 5, 287-290. [CrossRef]

27. Cui, F.Z.; Lin, Y.B.; Zhang, D.M.; Tian, M.B. Irradiation effects on secondary structure of protein induced by keV ions. Radiat. Phys. Chem. 2001, 60, 35-38. [CrossRef]

28. Susi, H.; Byler, D.M. Protein structure by Fourier transform infrared spectroscopy: second derivative spectra. Biochem. Biophys. Res. Commun. 1983, 115, 391-397. [CrossRef] 
29. Santos, M.V.; Pecoraro, É.; Santagneli, S.H.; Moura, A.L.; Cavicchioli, M.; Jerez, V.; Rocha, L.A.; de Oliveira, L.F.C.; Gomes, A.S.L.; de Araújo, C.B.; et al. Silk fibroin as a biotemplate for hierarchical porous silica monoliths for random laser applications. J. Mater. Chem. C 2018, 6, 2712-2723. [CrossRef]

30. Wu, X.; Wu, X.; Shao, M.; Yang, B. Structural changes of Bombyx mori fibroin from silk gland to fiber as evidenced by Terahertz spectroscopy and other methods. Int. J. Biol. Macromol. 2017, 102, 1202-1210. [CrossRef]

31. Riekel, C.; Müller, M. In Situ X-ray Diffraction during Forced Silking of Spider Silk. Macromolecules 1999, 32, 4464-4466. [CrossRef]

32. Sinsawat, A.; Putthanarat, S.; Magoshi, Y.; Pachter, R.; Eby, R.K. X-ray diffraction and computational studies of the modulus of silk ( Bombyx mori). Polymer 2002, 43, 1323-1330. [CrossRef]

33. Song, R.; Ino, H.; Kimura, T. Mechanical Property of Silk/Bamboo Composite Paper for Effective Utilization of Waste Silk. J. Text. Eng. 2009, 55, 85-90. [CrossRef]

34. Song, R.; Kimura, T.; Ino, H. Papermaking from Waste Silk and Its Application as Reinforcement of Green Composite. J. Text. Eng. 2010, 56, 71-76. [CrossRef]

35. Song, R.; Kimura, T. Effect of PVA Binder on the Mechanical Properties of Silk/Bamboo Paper-Reinforced PBS Green Composite. Fiber 2012, 68, 172-177. [CrossRef]

36. Rajkumar, G.; Srinivasan, J.; Suvitha, L. Development of novel silk/wool hybrid fibre polypropylene composites. Iran. Polym. J. 2013, 22, 277-284. [CrossRef]

37. Nogueira, G.M.; Rodas, A.C.D.; Leite, C.A.P.; Carlos, G.; Higa, O.Z.; Bronislaw, P.; Beppu, M.M. Preparation and characterization of ethanol-treated silk fibroin dense membranes for biomaterials application using waste silk fibers as raw material. Bioresour. Technol. 2010, 101, 8446-8451. [CrossRef]

38. Gaviria, A.; Sanchezdiaz, S.; Ríos, A.; Peresin, M.S.; Restrepoosorio, A. Silk fibroin from silk fibrous waste: characterization and electrospinning. IOP Conf. Ser. Mater. Sci. Eng. 2017, 254, 102005. [CrossRef]

39. Yao, Y.; Mukuze, K.S.; Zhang, Y.; Wang, H. Rheological behavior of cellulose/silk fibroin blend solutions with ionic liquid as solvent. Cellulose 2013, 21, 675-684. [CrossRef]

40. Xiao, H.; Kaplan, D.; Cebe, P. Determining Beta Sheet Crystallinity in Fibrous Proteins by Thermal Analysis and Infrared Spectroscopy. Macromolecules 2006, 39, 6161-6170. [CrossRef]

41. Tretinnikov, O.N. Influence of Casting Temperature on the Near-Surface Structure and Wettability of Cast Silk Fibroin Films. Langmuir 2001, 17, 7406-7413. [CrossRef]

42. Arrondo, J.L.; Muga, A.; Castresana, J.; Goñi, F.M. Quantitative studies of the structure of proteins in solution by Fourier-transform infrared spectroscopy. Prog. Biophys. Mol. Biol. 1993, 59, 23-56. [CrossRef]

43. Krimm, S.; Bandekar, J. Vibrational Spectroscopy and Conformation of Peptides, Polypeptides, and Proteins. Adv. Protein Chem. 1986, 38, 181-364. [CrossRef] [PubMed]

44. Lu, Q.; Zhang, B.; Li, M.; Zuo, B.; Kaplan, D.L.; Huang, Y.; Zhu, H. Degradation mechanism and control of silk fibroin. Biomacromolecules 2011, 12, 1080-1086. [CrossRef] [PubMed]

45. Reinstadler, D.; Backmann, F.I.; Naumann, D. Refolding of Thermally and Urea-Denatured Ribonuclease' A Monitored by Time-Resolved FTIR Spectroscopy. Biochemistry 1996, 35, 15822-15830. [CrossRef] [PubMed]

46. Boulet-Audet, M.; Vollrath, F.; Holland, C. Rheo-attenuated total reflectance infrared spectroscopy: A new tool to study biopolymers. Phys. Chem. Chem. Phys. 2011, 13, 3979-3984. [CrossRef] [PubMed]

47. Minoura, N.; Aiba, S.; Higuchi, M.; Gotoh, Y.; Tsukada, M.; Imai, Y. Attachment and growth of fibroblast cells on silk fibroin. Biochem. Biophys. Res. Commun. 1995, 208, 511-516. [CrossRef] [PubMed]

(C) 2019 by the authors. Licensee MDPI, Basel, Switzerland. This article is an open access article distributed under the terms and conditions of the Creative Commons Attribution (CC BY) license (http://creativecommons.org/licenses/by/4.0/). 